\title{
Strategic Information System Planning: A Case Study of a Service Delivery Company
}

\author{
Samar Alamri ${ }^{1}$, Noura Almutiri ${ }^{2}$, Hanaa Ballahmar ${ }^{3}$, Aasim $_{\text {Zafar }}{ }^{4}$ \\ Department of Information Systems, Faculty of Computing and Information Technology, \\ King Abdulaziz University, Jeddah, Kingdom of Saudi Arabia ${ }^{1,2,3,4}$
}

\begin{abstract}
Strategic Information Systems Planning (SISP) is a critical task that enables organizations to establish crucial IT tools and align a company's strategic plan with reliable IT solutions with the aim of attaining the objectives and goals of the company. At present, improved strategic information planning is one of the vital issues that face current information systems. Thus, the planning of strategic information technology solutions plays a critical role that contributes to the business and success of an organization. This paper offers an overview of Strategic Information Systems Planning (SISP) in an IT service company of KSA. The paper reviews a case study of the Saudi Telecommunications Company (STC). STC applies SISP strategies to increase its international operations, increase customer satisfaction and help the company to offer its convergence solutions to all centres across the globe. The paper briefly describes the role and importance of SISP, the primary phases and success factors, a service company, the service delivery process in the company, the role of SISP in enhancing a service delivery model in the IT services company and a conclusion.
\end{abstract}

Keywords: IT Service Delivery Model, Strategic Information Systems Planning (SISP), Strategic Planning, and Information Systems Planning.

\section{INTRODUCTION}

Strategic Information Systems Planning (SISP) is a is vital to an organization in terms of reaching a concept that can be dated back to the early 80s [1]. Since competitive advantage. This paper covers the strategic then, SISP has been recognized for the contribution it has information system and focuses on the critical success made to companies. Additionally, the concept has become factors of SISP implementation with regard to an IT a challenging subject for practitioners and scientists in the service delivery company. past two decades. SISP enables organizations to succeed in the world's current highly competitive environment. In effect, many researchers have performed studies aimed at assisting in making the deployment of SISP more profitable and effective.

Strategic Information Systems Planning (SISP) refers to the identification and categorization of various computerbased applications with the main intent of assisting an organization to execute its business strategies and accomplish set objectives. SISP has gained popularity over the years due to the importance of aligning the process of developing an information system with a company's system development plan. Such an ideal scenario assists corporations in different subsectors to maximize the benefits of the recently introduced technologies [3]. Organizations benefit from SISP by increasing their competitive advantage over other firms, developing new businesses, identifying effective management procedures and improving the productivity of human resources. SISP acts as a link between different professionals. Subsequently, a firm's management can identify the priorities in information system development.

Therefore, for a company to be successful, it should develop a reliable strategic plan aimed at driving strategic information systems planning. Planning of information systems that is strategically aligned with business planning

\section{SISP}

SISP development occurs in five major phases. Firstly, the strategic business planning phase acts as a stable foundation for further development proceedings. The duties executed at this stage include the identification of the firm's objectives and the suitable approaches to accomplishing them, SWOT analysis and the corporation's mission. Subsequently, the developers conduct a detailed information systems assessment to evaluate its current status.

Other crucial phases are the information systems vision and guidelines and strategic initiatives [5]. A third phase is information system assessment where the system is evaluated by evaluating the current system resources in order to find out how they are serving the organization. Another phase is information system guidelines. This is a set of statements that guide the use of information system resources. Finally, the strategic initiatives phase is a longterm proposal (taking up to five years) that specifies new initiatives [3]. The success of SISP depends on the developers' ability to ensure a proper alignment among the relevant components.

The figure below graphically summarizes the SISP process. 


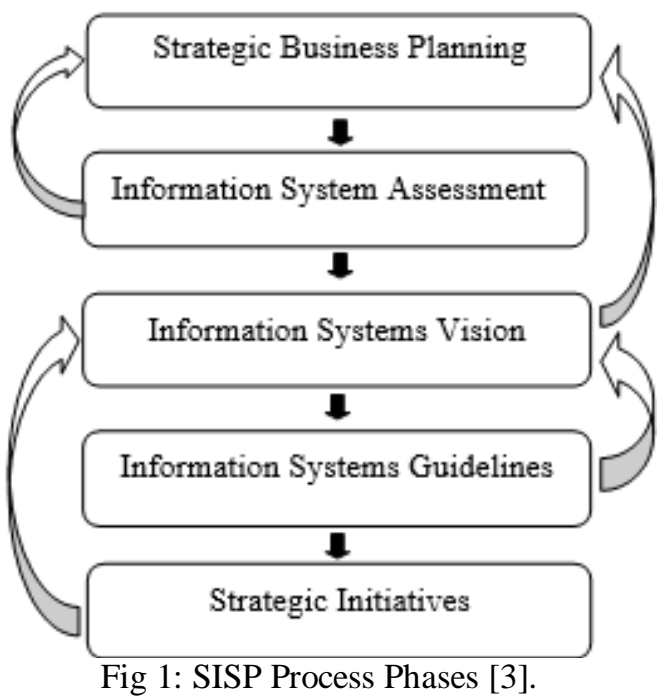

A. SISP's Role and Important

SISP would be beneficial in accomplishing the short and long-term goals of an IT service firm, such as increasing the customer base, addressing and solving problems and controlling cost. The corporation, which is one of the wellestablished IT services companies in the Kingdom of Saudi Arabia (KSA), offers various professional services linked to human resource management. Based on the essence of a stable information system in increasing a firm's competitiveness and its employees' performance, SISP will be useful in fulfilling the mission of this IT services firm. The service delivery model integrated into SISP is a complex yet critical element in information system development. It encompasses such aspects as the presentation of the client's requests, service proposal development, execution of the formulated strategy and project management [4]. The model aims at encompassing the parties involved in the development process from the attainment of the customer's requests to the delivery of the required services based on his or her specifications. SISP is useful in connecting the relevant stakeholders in the IT services corporation, an aspect that results in customer satisfaction and an increase in the corporation's competitive advantage over other participants in the target market [10]. For instance, in the case of the Saudi Services Company, SISP will be helpful in linking human resources to the managers looking for employees with specific skills. Accordingly, the alignment process will offer lasting solutions to the clients while facilitating the accomplishment of the short and long-term goals set by the IT services firm in question. For instance, through the multifaceted information system established in this company, the management will be in a position to source professionals with certain qualifications online. The approach will be efficient in ensuring customer satisfaction, an aspect that will result in its operational growth. SISP is a suitable development tool in the organizational setting of the IT services company under review.

\section{B. SISP Success Factors}

Implementing a successful SISP is critical for an enterprise. This accomplishment is directly connected to the overall success of an organization, which is based on whether an organization is meeting its objectives or not. Therefore, different strategic directions are used to determine the success of an organization, which can further be applied to determine the success of the SISP.

[3] view SISP success as the degree of attaining the predetermined goals and objectives. Their study offered four dimensions of SISP objectives, including alignment, analysis, improvement in capabilities and cooperation. The alignment success dimension promotes a company's understanding of the information system. Thus, as a success factor, greater alignment leads to an improved effectiveness of the SISP. Secondly, analysis involves the understanding of an organization's internal operations. Analysis helps planners to develop a clear understanding of a company's important procedures and processes. Cooperation helps stakeholders to ensure that the management and other users collaborate to make the SISP process and content a success, a process that reduces the possible risks that may lead to SISP implementation process failure. The last success, capability enhancement, involves the improvement of the potential of the SISP.

A successful SISP enables a firm to tap into future opportunities and to exploit the skills available in the organization. This process is vital for profit maximization and cost effectiveness. For an SISP to be successful, planning before the development and deployment of the SISP is vital. The cost involved is high, and practitioners recommend that there is a critical need for clarity of the plan associated with the implementation of a successful SISP [8].

The development and configuration processes of SISP influence the success of SISP. In other words, the authors' explorative multi-case study found that the comprehensiveness, specificity, decisions and goals of an organization have a positive effect or are critical success factors of SISP. Additionally, a dominant role of an IS/IT company in the SISP process influences the quality of SISP delivery in a positive way. However, the dominant role can have a negative impact on the partnership between IT and business functions in an organization.

Researchers also conclude that following a formal SISP methodology does not determine the success of implementing SISP in an organization [8].

\section{III.THE SAUDI SERVICE COMPANY}

IT services firms in the Kingdom of Saudi Arabia offer different professional services that are linked to human resource management. The firms offer the services following internationally accepted policies and procedures while utilizing modern solutions and IS/IT tools with a focus on diversifying their services to reach other regions in the continent and globally and on vertically covering specialists and new markets. The service firms' focus is on positioning to be the preferred providers to their clients in an environment faced by stiff competition and evolving solutions. 
A. The Service Delivery Process in an IT Company

Running a successful IT service company should be synonymous with the delivery of excellent service. The key differentiator for service companies lies in the service management model and the ability to execute that model. Designing a service delivery system should put more focus on the factors that create value for the organization and engage frontline employees to deliver the best customer experience. The process should be affected by the client's request, the service proposal development, the service execution and the project management.

[7] Highlights a successful service delivery process in an IT company. The first element is the service culture. It should be built on elements of norms, leadership principles, visions, work habits, values and missions. The set of these overriding principles gives value to the customer. Thus, the service culture should aim at developing a superior service delivery system and a realistic service concept to ensure that the organization has established long-term success. Secondly, employee engagement should include purpose driven leadership and reliable HR processes. Service quality is the third element, including processes, strategies and performance management systems. The design of the service quality element should help the customer fulfil their mission and support them in the pursuit of his/her purpose. The fourth element is customer experience, including elements such as customer intelligence, continuous improvement and account management. The service delivery process is highly dependent on the role of SISP.

\section{B. The Role of SISP in Enhancing the Service Delivery Model}

In the past, traditional product-based companies struggled to demonstrate cost savings. However, service companies are focusing on ways to add value to a business. Thus, the IT/IS should put more emphasis on the alignment with a business. SISP's core argument holds that a firm's information systems investment should be aligned with the overall objectives and business strategy and may become a vital source of competitive advantage [9]. Thus, a firm should study and understand how the alignment takes place and establish measurable benefits.

Through SISP, companies can achieve an IS-based competitive advantage and alignment. The process requires an organization to follow a formal, comprehensive and proactive process that involves the development of broad organizational information requirements. Unlike an IT service company, a traditional product-based organization sits back and responds to areas of the business after a need arises. Therefore, SISP introduces a proactive strategy relevant to IT service companies, given their long-term impact and the costs of investment.

Six dimensions that define a successful SISP process in enhancing the service delivery process. Comprehensiveness is the first dimension. It refers to the extent to which a service company attempts to be inclusive and exhaustive in integrating and making strategic issues. Formalization is the second dimension and represents the existence of techniques, structures, policies and procedures that guide the planning process. Focus involves a balance between control orientations and the creativity inherent in the strategic planning system. A reliable and innovative orientation focuses on innovative solutions to deal with threats and opportunities. The top-down flow dimension recommends that top managers should implement SISP while other staff should offer support. Even though SISP planning is top-down, a broad participation dimension is needed where all functional areas are required to participate. It also includes the key stakeholders at other levels of a company. SISP should maintain high consistency. This can be achieved through frequent meetings as well as a regular reassessment of the overall SISP strategy [6].

\section{SISP PLAN: A CASE STUDY OF STC}

This section intends to offer some insight into how KSA organizations handle their SISP. Notably, research shows that less than a quarter of SISP approaches adopted by organizations are effective [2]. Organizations with formally effective cases of an SISP strategy enjoy a higher rate of IS/IT success regarding adding value and suitability to the business in terms of user acceptance. Additionally, organizations with such SISP strategies can cope with the dynamics and changes associated with rapidity in the IT environment and are able to achieve their organizational goals and a better competitive advantage.

The application of SISP in Arab country companies shows large investments that require managers to determine if the investments are creating value for investors. SISP in KSA companies is a critical stage that decides how IT should be spent to increase value and competitive advantage. The Saudi Telecommunications Company (STC) is a large telecommunications provider in KSA. STC applies SISP strategies to increase its international operations and customer satisfaction and to help the company offer its convergence solutions to all centres across the globe.

\section{A. Methodology}

A qualitative approach for this study is utilized for primary exploration research. The qualitative approach helps gain profound understanding of SISP in STC. We connected with Mr Ahmed Moushiqeh, GM of Consumer Planning and Performance at STC. Mr Moushiqeh operates at the STC head branch in Riyadh. Mr Moushiqeh answered the questionnaire, which helped in the investigation of the perspective of the company in the practice of SISP.

In addition, we used an online survey to collect data to examine the critical success factors for the practice of SISP in STC. It is suitable for this study because they can reach a greater number of STC staff across the country anytime and anywhere. The survey was announced through emails and social media for employees and was run from March 20, 2016 until April 1, 2016.

Notably, this study uses survey questions to clearly state which stakeholders in an organization are responsible for the successful management of SISP success predictors. The data collected using the survey questions are related to the SISP of STC since the data help establish the success indicators and the stakeholders responsible for the 
successful deployment of SISP at the company. For instance, the survey questions helped assess the management's involvement in the support and planning effort at STC. The findings analysed from the survey question results will be compared critically with the overwhelming consensus in the related literature.

The main objective of conducting a survey in this study was to uncover specific answers to the research questions. The questionnaire was critically prepared to ensure that it met the main objective of carrying out the survey. The survey involved administering strategically structured and planned questions in an appropriate way to collect the most accurate data regarding the application of SISP at STC.

\section{B. Finding}

The company implements emerging technologies, has succeeded in serving millions of calls every day and has created favourable revenue trends for the company. The company reviews its SISP strategy through emphasizing customer satisfaction as a critical objective. SISP offers the company improved business processes, increased customer satisfaction and an enhanced effectiveness of the business processes. The Saudi Telecommunications Company (STC) applies SISP strategies to increase its international operations and customer satisfaction and to help the company to offer its convergence solutions to all centres across the globe. In effect, the technical team and sales personnel can share problems and solutions. $\mathrm{Mr}$ Moushiqeh indicated that STC is currently focusing on internal processes. The aim is to be recognized as a leading information and communications technology provider of comprehensive and innovative services and solutions, to earn the trust of customers and to enrich the community. Thus, it has highlighted some aspects, such as being customer first and innovative, leading with agility, building trust and being one STC team. Furthermore, Mr Moushiqeh mentioned that STC currently focuses on KSA only rather than focusing internationally through the development of a Lead Strategy. This strategy makes the company focus on collective energies and efforts to exploit emerging opportunities while also enabling it to manage future challenges. It depends on six major aspects that are important to the company:

- Leadership in providing a new generation of broadband services by making the company the first choice for broadband services by providing content, innovative applications and integrated services and access to these services in multiple ways,

- Excellence in customer service by meeting customer expectations to provide integrated experiences offering featured and innovative services designed specifically for customers,

- Promoting international leadership to increase the international investment portfolio and to expand in the Middle East and North Africa and achieving synergies and integration among the products and services, technology and the supply chain with the construction of distinct capabilities to manage international operations,
- Investment of human capital in leadership development and promising talent, raising the level of professional association of the staff and building an institutional and successful work culture with an attractive environment,

- Enhancing the flexibility of financial performance to optimize shareholder value and the continued enhancement of financial performance and the efficient use of resources and investment to ensure profitable growth over the long term,

- Consolidate the leading position attribute and the leading feature of the company through effective communication with key beneficiaries highlighting the high value of the company and its leading role in economic and social development and status,

An online survey was distributed to STC employees in order to examine the knowledge of the employees in the organization regarding the strategic information system planning of the company. The survey was taken by 75 employees from different levels, including MIS managers, top managers, call centre employees, system analysts, programmers, consultants and computer operations personnel. The result of each question of the survey is discussed below:

MIS managers

$\square$ Top managers

$\square$ Non-MIS managers

$\square$ System analysts

$\square$ Programmers

$\square$ Consultants

$\square$ Computer operations personnel

MIS managers

$\square$ Top managers

$\square$ Non-MIS managers

$\square$ System analysts

$\square$ Programmers

$\square$ Consultants

$\square$ Computer operations personnel

- The employees were asked if they believe that the top management are supporting the planning effort, and the result shows that most of the employees agree while only $4 \%$ disagree,

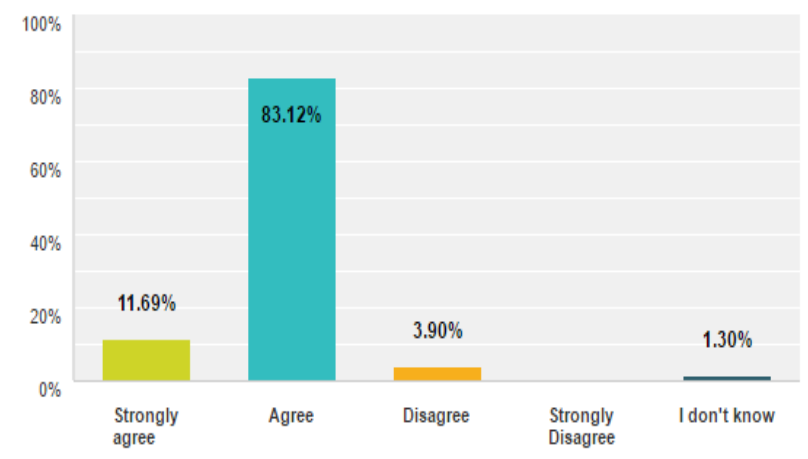

Fig 2: The presence of support from top management of the planning efforts in STC

The participants were asked if they felt that the company is hiring qualified people who are able to do the required job, and the results are as shown below, 


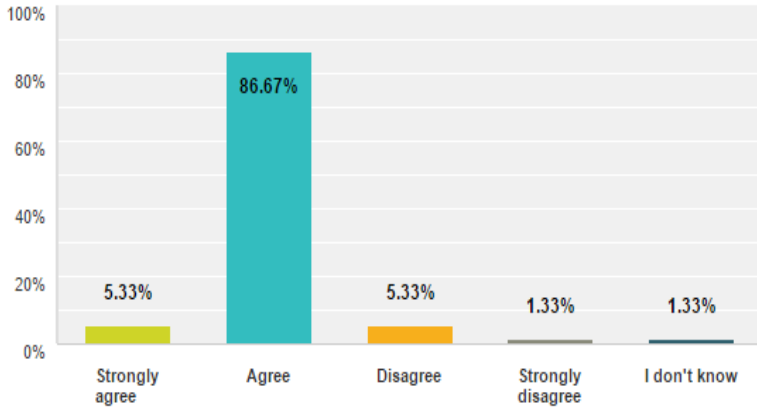

Fig 3: The ability of STC to recruit qualified staff

According to the above results, more than $90 \%$ of the participants agree that the company is hiring the right staff for the job. However, as shown in the result above, there may be a misuse of human resources in some areas of the company. In effect, some of the people responsible for implementation of SISP at STC might be failing to play their part.

- The participants were asked if they believed that the information system strategy in STC is clear enough to guide the planning effort. The results are as shown,

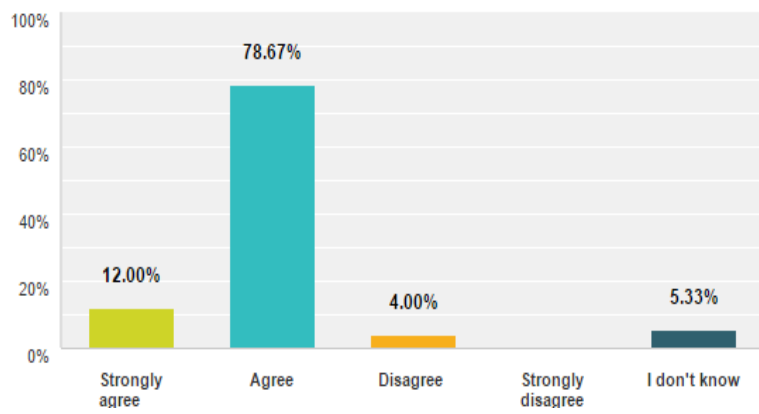

Fig 4: The information system strategy in STC is clear enough to guide the planning effort

According to the employees' response, around 7\% of the employees did not have any knowledge about the strategic plan of the company.

- The survey also sought to establish what the participants thought about STC expecting possible changes in the field of information technology and environmental changes, which may affect the strategic IS planning process,

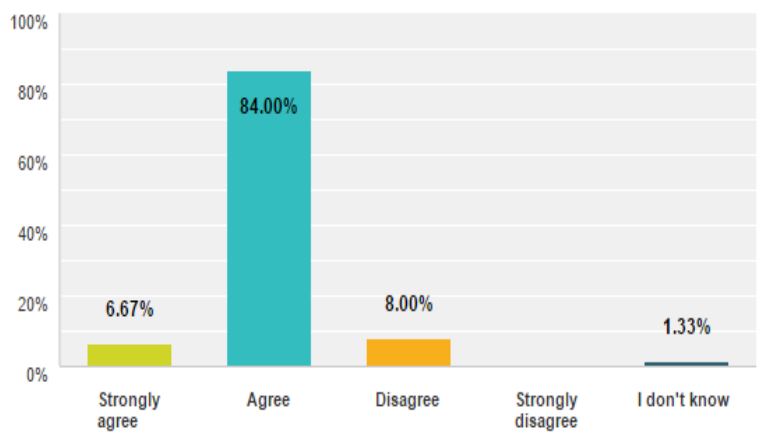

Fig 5: The ability of STC to expect possible changes in the field of information technology and environmental changes
According to the data above, more than $90 \%$ of the employees believed that the organization expected possible changes in IT, which may affect the IS planning process.

- $\quad$ The employees were asked if they believe that STC is having free communication and a commitment to change the thought of the organization. The employees' response to this question shows a good level of flexibility regarding the company's ability to adapt change, with more $89.33 \%$ agreeing.

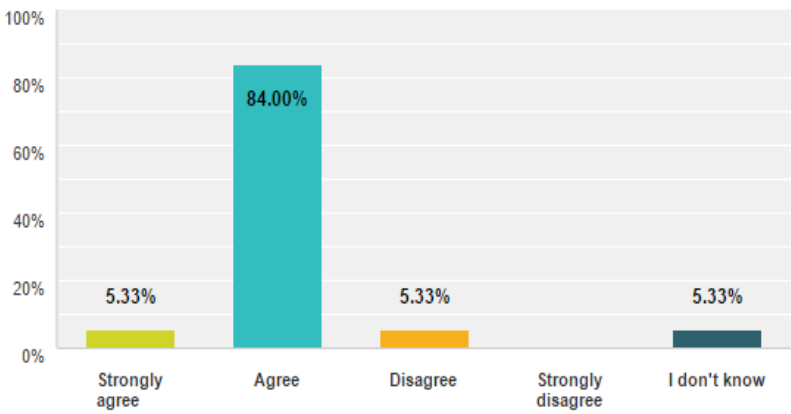

Fig 6: STC has a free connection and its commitment to change the thought of the organization

- When asked if the company STC invests enough "front end" time to ensure that all planning tasks and responsibilities of the individual were understood, the participant responded as shown in the graph below.

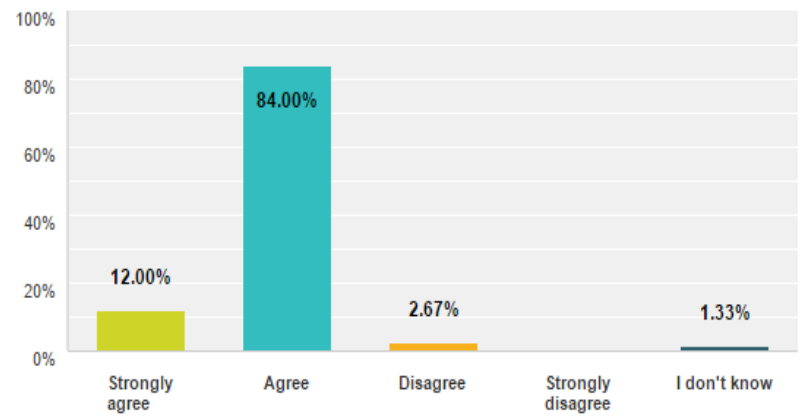

Fig 7: the ability of STC to invest enough "front end" time to ensure that all planning tasks and responsibilities of the individual are understood

- $\quad$ The employee were asked if the company STC has clear, concise, and formal planning procedures. The responses are shown below.

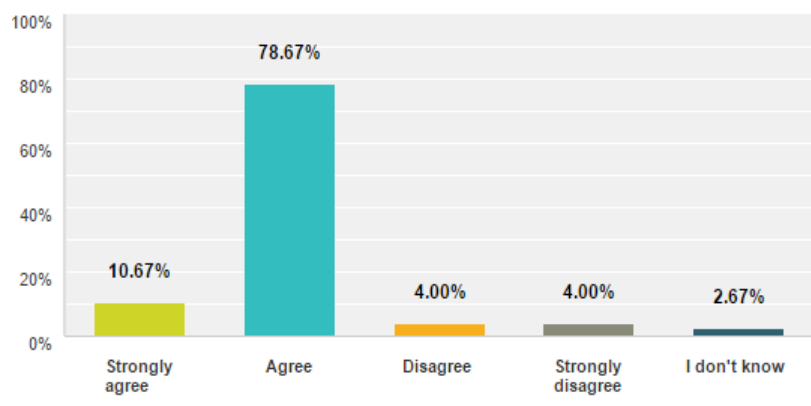

Fig 8: STC has clear, concise and formal planning procedures 
- The employees were asked if the company STC decides on the appropriate planning horizon.

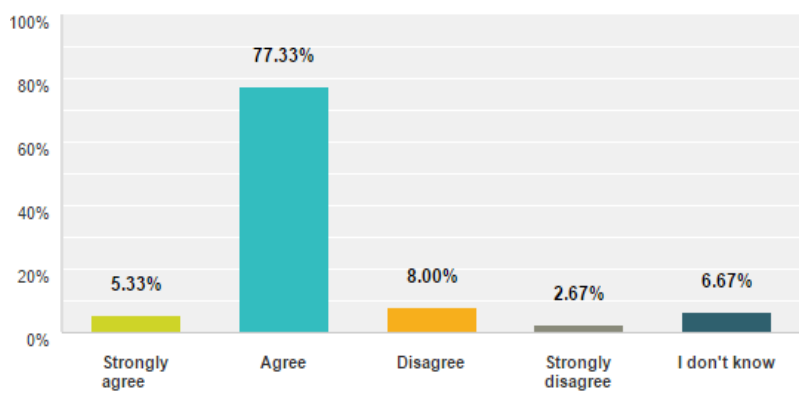

Fig 9: The ability of STC to decide on the appropriate planning horizon

- $\quad$ The company STC is taking into account the people and politics side of strategic information system planning.

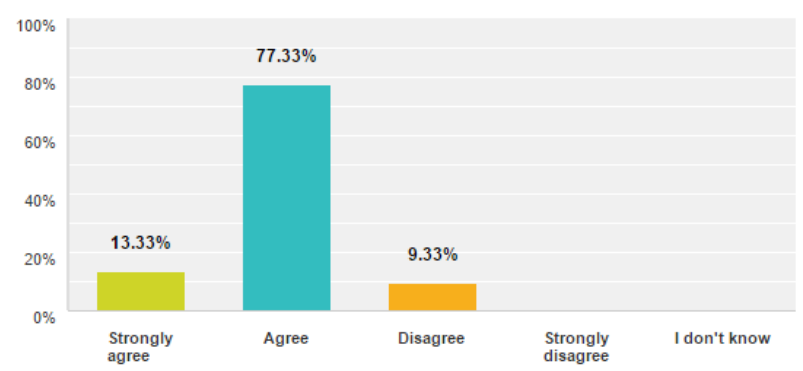

Fig 10: The ability of STC to take into account the people and politics side of strategic information system planning

\section{Discussion/Analysis}

As shown above, the preparation and administration of the questionnaire was followed by a process of selecting an adequate statistical test for examining the usefulness of SISP. The selected test is simple and robust enough to meet the objectives of the survey.

As a result, the study indicates that the ability of STC to recruit qualified staff represented the main factor for the success of SISP. As for the ability of STC to expect possible changes in the field of information technology and environmental changes that may impact the SISP process, STC has a free connection and its commitment to change the thought of the organization and the ability of STC to invest enough "front end" time to ensure that all planning tasks and responsibilities of the individual are understood rank second for the success factor of SISP. The presence of support from top management of the planning efforts ranks third for the success factor of SISP. The information system strategy in STC is clear enough to guide the planning effort and STC has clear, concise and formal planning procedures rank forth for the success factor of SISP. The ability of STC to decide on the appropriate planning horizon and to take into account the people and politics side of strategic information system planning ranks last.

The responses of the questionnaire and survey that were conducted regarding the practice of the SISP in STC confirmed that the practice of the SISP process in STC leads to its success. Though senior management plays a very important role in strategic planning, we expect the participation of information system management to add a significant value to SISP.

As discussed earlier, SISP phases can be deployed to an STC IT Service Company. There is a link between business strategic planning and development and the implementation of strategic initiatives. The company's strategy is developed to focus on collective energy and efforts in capturing emerging opportunities while managing overall challenges.

STC Information System Assessment involves evaluating the system to assess the status or current information systems resources in terms of current or original expectations and how they are serving the organization. The process involves assessing the current applications, current data collections, current information technology and short-term IS improvement plan. Furthermore, the process of measuring the benefits and costs of information systems is often the cause of uncertainties about the expected impact of the system. Thus, decision makers face this challenge without the use of SISP.

STC has developed the ideal role that should be pursued for the use of information systems resources. This is the information systems vision. STC wants to be recognized as the ICT leader in providing comprehensive innovative services and solutions while enriching society and earning customer trust. The company has developed information system guidelines that clarify the use of STC's technical and information systems resources.

The importance of SISP in STC is helping the company achieve its bottom line. The solution helps STC track competition and latest global trends and brings the best ideas to the market for mobile communications, landlines, the Internet and other services offered by the company.

In the long term, STC's SISP has evolved in style and method on the basis that it emphasizes the need to bring IT to align and influence the company's strategic direction. STC has gained a recognized relevance in terms of competitiveness because of SISP. The degree to which the strategic direction of telecommunication services and products aligns with IT influences the competitiveness of STC. After analysing the data, we found out that the employees' awareness of the company's strategic plan is at a good level. This gives the company an advantage of employee loyalty and employees become part of the company's improvement and growth; this was the objective of conducting the survey.

\section{CONCLUSION}

Improving SISP is a critical issue for organizations today. Successful planning is vital to the success and realization of the potential strategic impact of an IT/IS system. SISP planning should be done in alignment with the business planning in an organization. Firms should institutionalize a formal top-down planning process in the SISP strategy. The process links the information systems strategy with a business's planning and needs. Finally, a survey was conducted for STC employees; the result of the survey shows that most of the employees have a clear understanding of the company's SISP and that they are, to some extent, adapted to it. Even though the company 
reached a good level of employee knowledge about SISP, still they need to enhance this knowledge to reach all employees.

\section{ACKNOWLEDGMENT}

The authors would like to thank King Abdulaziz University, which offered all the required support and resources through the Saudi Digital Library (SDL).

\section{REFERENCES}

[1] Alaboud F (2011) Strategic information systems planning: a brief review. IJCSNS International Journal of Computer Science And Network Security 11(5), 179-183.

[2] Albadri F (2010) Strategic information systems planning in UAE organizations: SISP approaches classifications. European, Mediterranean, and Middle Eastern conference on information Systems 2010 (EMCIS2010).

[3] Altameem, A., Alidrees, A., \& Aisaeed, N. (20142). Strategic information systems planning (SISP). Proceedings of the World Congress on Engineering and Computer Science.

[4] Galliers R \& Leidner, D (2003) Strategic Information Management: Challenges and Strategies in Managing Information Systems. Oxford, Butterworth-Heinemann.

[5] Khosrow-Pour, M. (2006). Cases on strategic information systems. Hershey, PA: Idea Group Pub.

[6] Segars, A.H., Grover, V., \& Teng, J.T.C. (1998). Strategic Information Systems Planning: Planning System Dimensions, Internal Coalignment, and Implications for Planning Effectiveness. Decision Sciences, 29(2,), 303-345.

[7] Servicefutures (2015). Four key elements of a service delivery system. http://servicefutures.com/service-management/four-keyelements-service-delivery-system, accessed 23 February 2016.

[8] Silvius, A.J.G., \& Stoop, J. (2013). The Relationship Between Strategic Information Systems Planning Situational Factors, Process Configuration, and Success. Journal of International Technology and Information Management, 22(1), 1-16.

[9] Teubner, R.A. (2007). Strategic Information Systems Planning: A Case Study from the Financial Services Industry. Journal of Strategic Information Systems, 16, 105-125.

[10] Ward, J., \& Peppard, J. (2002). Strategic planning for information systems. Chichester, UK: J. Wiley. 